\title{
ASSEGURAR OU NÃO ASSEGURAR? EIS A QUESTÃO: UMA ANÁLISE DOS FATORES ASSOCIADOS À ASSEGURAÇÃO DOS RELATÓRIOS DE SUSTENTABILIDADE
}

\begin{abstract}
Assure or not assure? Here's the question: An analysis of the factors of voluntary assurance on sustainability reports
\end{abstract}

Gabriela Borges Silveira

E-mail: gabi_confiante@yahoo.com.br Mestra e Doutoranda em Contabilidade pela Universidade Federal de Santa Catarina; Bolsista no Programa de Pós-graduação em Contabilidade da Universidade Federal de Santa Catarina. Endereço para contato: Rua Eng. Agronômico Andrei Cristian Ferreira, Centro Socioeconômico, Prédio F, s/n, Trindade, 88040-900, Florianópolis, Santa Catarina, Brasil. https://orcid.org/0000-0003-2950-4037

Mestra e Doutoranda em Contabilidade pela Universidade Federal de Santa Catarina; Bolsista no
Programa de Pós-graduação em Contabilidade da Universidade Federal de Santa Catarina.
https://orcid.org/0000-0003-3911-6855

Robson Benedito Farias E-mail: farias.robson@gmail.com

Mestre em Contabilidade pela Universidade Federal de Santa Catarina; Bacharel em Ciências Contábeis pela Universidade Federal da Grande Dourados; Professor Substituto na Universidade Estadual de Mato Grosso do Sul. https://orcid.org/0000-0002-4587-4276

Hans Michael Van Bellen E-mail: hans.michael@ufsc.br Doutor em Engenharia de Produção pelo Programa de Coop. Internacional-Doutorado Sanduíche pelo Universität Dortmund, Alemanha; Professor Associado na Universidade Federal de Santa Catarina. https://orcid.org/0000-0002-9224-7232

Suliani Rover

E-mail: sulianirover@gmail.com

Doutora em Controladoria e Contabilidade pela Universidade de São Paulo; Professora no Departamento de Ciências Contábeis e no Programa de Pós-graduação em Contabilidade da

Universidade Federal de Santa Catarina. https://orcid.org/0000-0001-8612-2938

Artigo recebido em 29 de abril de 2019. Aceito em 30 de julho de 2019. 


\section{Resumo}

Asseguração é processo voluntário de verificação externa que objetiva atribuir confiabilidade e transparência às informações contidas nos Relatórios de Sustentabilidade (RS). Desse modo, esta pesquisa teve por objetivo verificar os fatores que estão associados à asseguração dos RS. A amostra deste estudo compreende as empresas listadas no índice IBrX-100 da B3 no período de 2011 a 2015. Por meio da técnica de Análise de Correspondência (Anacor) realizou-se o Teste Qui-quadrado entre as variáveis: Impacto, Ativo, Receita Líquida, ROA, ROE, Endividamento, ADR, Setor Regulado, ISE, Governança Corporativa, Auditoria e GRI e a asseguração dos RS em cada ano. E para visualizar as associações, por meio de mapas perceptuais, utilizou-se a Análise de Homogeneidade (HOMALS). De acordo com os resultados, quatro variáveis se mostraram mais associadas à asseguração dos RS em todos os anos: Setor Regulado, ISE, GRI e Auditoria. Esses achados sugerem que as empresas atuantes em setores regulados e com maiores práticas de sustentabilidade estão mais associadas à asseguração dos RS. Além disso, a asseguração é realizada em sua maioria por empresas de auditoria, e o padrão mais utilizado na elaboração dos relatórios é o GRI. Palavras-chave: Relatório de Sustentabilidade. Disclosure Socioambiental. Asseguração.

\section{Abstract}

This research had as objective to verify the factors associated with the voluntary assurance on Sustainability Reports (SR). The sample of this study comprises the companies listed in the $\mathrm{IBrX}-100$ index of $\mathrm{B3}$ and the period from 2011 to 2015. Through the technique of Correspondence Analysis (Anacor), the Chi-square Test was performed between the variables: Impact, Asset, Net Revenue, ROA, ROE, Indebtedness, ADR, Regulated Sector, ISE, Corporate Governance, Audit and GRI and assurance of RS in each year. In order to visualize the associations, by means of perceptual maps, the Homogeneity Analysis (HOMALS) was used. According to the results, four variables were more associated with the assurance of SR in all years, being: Regulated Sector, ISE, GRI and Audit. These findings suggest that companies operating in regulated sectors and with greater sustainability practices are more associated with SR assurance. In addition, assurance is performed mostly by audit firms, and the GRI is the most used reporting standard.

Keywords: Sustainability Report. Socioenvironmental Disclosure. Assurance.

\section{INTRODUÇÃO}

De modo a se adaptarem às práticas ambientais exigidas pelos stakeholders e propostas pelas tendências mundiais, os gestores informam sua interação com o meio ambiente em busca de maior disclosure, accountability e boas práticas de governança corporativa (Rover, Borba, Dal-Ri Murcia, \& Vicente, 2008) e o fazem por canais diferenciados e voluntários: websites elou Relatórios de Sustentabilidade (RS). As publicações são baseadas em importantes direcionadores de mercado, como a Global Reporting Initiative (GRI), a Norma Brasileira de Contabilidade NBCT 15-Informações de Natureza Social e Ambiental e o Relato Integrado.

Como esses relatórios mencionados não são obrigatórios, o mercado busca uma forma de legitimá-los de modo que os stakeholders estejam assegurados das informações ali 
contidas. Segundo Patten (1992), as divulgações socioambientais podem ser vistas como um método de resposta às percepções em mutação dos públicos relevantes de uma organização.

Dessa maneira, a importância dada aos RS ocorre porque somente os relatórios financeiros não traduzem o desempenho global da organização aos interessados da informação (Gomes, 2012), sendo percebida a necessidade de, além de elaborar o documento, certificá-lo por meio de asseguração independente. Nesse aspecto, Hodge, Subramania, e Stewart (2009) questionaram o aumento do número de divulgação dos RS sem o devido aumento do nível de confiança pública.

Asseguração refere-se ao processo de verificação externa que visa a atribuir confiabilidade e transparência às informações contidas nos RS acerca da finalidade e do desempenho do negócio (Perego \& Kolk, 2012; Global Reporting Initiative [GRI], 2013). Apesar de voluntária, a asseguração tem se tornado uma importante ferramenta na construção da reputação corporativa, uma vez que alguns benefícios internos e externos da garantia podem ser facilmente identificados, como aqueles relacionados à construção da confiança direcionada às áreas de governança, gestão e relações das partes interessadas (GRI, 2013).

Simnett, Vanstraelen, e Chua (2009) explicam que as empresas tomam por relevantes os serviços de asseguração, quando os benefícios derivados dela são percebidos, compensando os custos que foram associados. Entre os benefícios relacionados pela literatura estão a mitigação dos custos de agência, o aumento da credibilidade dos gestores e a diminuição do custo de capital das empresas (Kolk \& Perego, 2010; Ruhnke \& Gabriel, 2013; Cho, Michelon, Patten, \& Roberts, 2014).

Dentro da temática da asseguração, estudos buscaram identificar fatores associados à decisão das empresas em assegurar os RS. Esses fatores foram investigados em nível de empresa, setor e país, a exemplo dos seguintes: tamanho (Simnett et al., 2009; Kolk \& Perego, 2010; Gomes, 2012; Cho et al., 2014); rentabilidade (Cho et al., 2014; Castelo Branco, Delgado, Ferreira Gomes, \& Pereira Eugénio, 2014; Ruhnke \& Gabriel, 2013); alavancagem financeira (Cho et al., 2014; Castelo Branco et al., 2014); setor (Simnett et al., 2009; Cho et al., 2014; Castelo Branco et al., 2014; Silveira, Alberton, \& Vicente, 2017); governança corporativa (Zhou, Simnett, \& Green, 2013; Silveira et al., 2017; Martínez-Ferrero \& GarcíaSánchez, 2017); Global Reporting Initiative (GRI) (Ruhnke \& Gabriel, 2013); e empresas de auditoria (Simnett et al., 2009; Zhou et al., 2013; Silveira et al., 2017).

Entre os países do mundo, o Brasil ocupa a décima quarta posição referente ao ranking das empresas que recorrem à verificação externa dos RS ("KPMG International," 2011). Ainda, observa-se que no contexto brasileiro há mecanismos que orientam a divulgação das informações sobre sustentabilidade, como as deliberações feitas pela Agência Nacional de Energia Elétrica (Aneel) no Despacho 3.034/2006 e a Resolução CMN 4.327/2014 emitida pelo Banco Central. 
Nesse contexto, surge o interesse em investigar a seguinte questão de pesquisa: "Quais os fatores que estão associados à asseguração dos Relatórios de Sustentabilidade nas empresas brasileiras?" Desse modo, o objetivo da pesquisa é identificar os fatores que estão associados à asseguração dos Relatórios de Sustentabilidade no Brasil.

O levantamento feito pela KPMG ("KPMG International," 2015) mostrou que 62\% das 250 maiores companhias listadas na Fortune Global 500 garantem externamente seus relatórios, o que motivou esta pesquisa a avaliar tal comportamento nas 100 ações entre as mais negociadas do mercado de capitais brasileiro ( $\mathrm{IBr} X-100)$ de janeiro a abril de 2017.

Assim, espera-se que esta pesquisa forneça algumas contribuições, como, por exemplo: identificar o panorama atual da asseguração dos RS no cenário brasileiro; identificar se os fatores associados à asseguração permitem compreender as motivações que levam empresas a submeterem seus relatórios à verificação externa; contribuir para esse campo de pesquisa recente no País, confrontando ou corroborando os estudos já realizados em outros países; e fornecer evidências sobre a atuação das empresas de auditoria nesse ramo, uma vez que a asseguração dos RS representa a possibilidade de mercado além da tradicional auditoria financeira. Além disso, pode contribuir para as discussões sobre uma possível regulamentação ou maior padronização dessa prática, em razão da falta de padrões, procedimentos e critérios estabelecidos para a elaboração e asseguração dos relatórios (Wallage, 2000).

\section{REFERENCIAL TEÓRICO}

Nesta seção apresentam-se os conhecimentos teóricos e resultados de estudos anteriores para a fundamentação da pesquisa e evolução do conhecimento sobre o tema, sobretudo em empresas brasileiras, delimitados em Asseguração dos Relatórios de Sustentabilidade e Estudos Relacionados.

\subsection{ASSEGURAÇÃO DOS RELATÓRIOS DE SUSTENTABILIDADE}

Com a finalidade de dar credibilidade às informações socioambientais divulgadas pelas empresas em seus RS, o processo de revisão de tais informações é referenciado de várias formas e inclui assurance, garantia externa, verificação, asseguração e certificação (GRI, 2013). Esta revisão deve ser feita por entidades externas e independentes da organização auditada, as quais, segundo o GRI (2013), podem ser divididas em três grupos: empresas de contabilidade (procedimentos de auditoria), empresas de engenharia (certificações técnicas) e empresas de serviços em sustentabilidade (especialistas). 
Os principais objetivos do trabalho de asseguração consistem em garantir a veracidade da informação; contribuir para a credibilidade de todo o processo de gestão; assegurar que os recursos estão sendo empregados de forma eficaz; contribuir para a melhoria contínua do processo de divulgação; assegurar aos stakeholders e potenciais investidores que os riscos de gestão estão sendo administrados com eficácia; e demonstrar o compromisso da entidade em melhorar o seu desempenho econômico, ambiental e social (GRI, 2013).

A Resolução 1.160/2009 NBC TO 3000 do Conselho Federal de Contabilidade [CFC] (2009) define que a asseguração é o trabalho no qual o profissional independente visa a "[...] obter evidências apropriadas e suficientes para expressar sua conclusão, de forma a aumentar - grau de confiança dos usuários previstos sobre o resultado da mensuração ou avaliação do objeto, de acordo com os critérios que sejam aplicáveis" (p. 4). Assim, o relatório de asseguração configura-se na emissão de opinião de um profissional independente que garanta que as informações divulgadas nos RS de uma organização sejam confiáveis (Almeida, 2014).

Hasan, Roebuck, e Simnett (2003) afirmam que a estrutura e o conteúdo dos relatórios de asseguração externa podem variar dependendo do escopo da garantia. A diversidade nos conteúdos de garantia também foi confirmada por Deegan, Cooper, e Shelly (2006) ao apontarem em seus estudos a necessidade de orientações e regulamentação na área, em razão da não compreensão por grande parte dos usuários da informação.

Para a asseguração dos RS, o Comunicado Técnico CTO Ol-Emissão de Relatório de Asseguração Relacionado com Sustentabilidade e Responsabilidade Social (CFC, 2015a), que tem por base o Comunicado Técnico Ibracon 07/2012, orienta que, enquanto não houver norma específica para o caso das Informações sobre Sustentabilidade e Responsabilidade Social, deverá ser utilizada a NBC TO 3000-Trabalho de Asseguração Diferente de Auditoria e Revisão-Resolução CFC 1.160/2009, norma brasileira contábil consoante à norma internacional ISAE 3000 Assurance Engagements Other than Audits or Reviews of Historical Financial Information emitida pelo IASB em 2003.

As normas NBC TO 3000 e ISAE 3000 não determinam que os relatórios tenham formato padrão, mas elementos básicos, como: título que indique claramente do que se trata o relatório de asseguração emitido; destinatário, identificando a parte ou as partes a quem o relatório de asseguração é dirigido; identificação do objeto e descrição das informações sobre esse objeto; identificação dos critérios; limitação inerente que seja significativa; declaração de que o trabalho foi realizado de acordo com a NBC TO 3000; resumo do trabalho realizado; conclusão do profissional independente; data do relatório de asseguração; e nome da firma e do auditor independente responsável técnico, números de seus respectivos registros profissionais e local de emissão do relatório.

Wallage (2000) discute as experiências iniciais da auditoria com relação aos serviços de garantia dos relatórios de sustentabilidade. Para fins de ilustração, o estudo 
faz referências à verificação de The Shell Report 2000, abordando questões relativas à estrutura dos relatórios, normas de asseguração, procedimentos técnicos e critérios de asseguração, independência e habilidade do auditor. $O$ autor afirma que a verificação dos RS é um serviço de garantia muito desafiador para os auditores em decorrência da falta de padrões, procedimentos e critérios estabelecidos para a elaboração e asseguração dos relatórios, isso porque há muita discussão sobre quais são os limites das responsabilidades ambientais e sociais das empresas. Assim, enquanto não houver consenso sobre a definição de "desenvolvimento sustentável" e o conhecimento de suas implicações para o negócio, as normas geralmente não podem se tornar aceitas.

O processo de asseguração dos relatórios de sustentabilidade no Brasil é considerado uma prática voluntária, ou seja, submeter as informações socioambientais à verificação externa é uma iniciativa por parte das empresas. Nesse aspecto, Mori, Best, e Cotter (2014) salientam que a asseguração é uma importante ferramenta na tentativa de as empresas prestarem contas aos seus stakeholders. Para Perego e Kolk (2012), os serviços de garantia dos RS proporcionam maior transparência e consenso sobre a finalidade do negócio, caracterizando a construção de diálogo eficaz entre as partes interessadas.

Nesse sentido, Meyer e Rowan (1977) afirmam que o processo de legitimação das instituições não resulta apenas da eficácia racional e de normas legais, mas também de objetivos, meios e fins coletivamente valorizados. Assim, a legitimidade das instituições pode ser atribuída como consequência de comportamentos isomórficos, isto é, uma prática passa a ser comum e respeitada a partir do momento em que as entidades adquirem comportamento semelhante.

\subsection{ESTUDOS RELACIONADOS}

Simnett et al. (2009) investigaram os fatores associados à escolha voluntária de assegurar os RS e da escolha do prestador de garantia de diferentes países. Os autores analisaram a garantia e a escolha do prestador em razão dos fatores relacionados à empresa, à indústria e ao país. Mais especificamente, a pesquisa verificou se os benefícios organizacionais resultantes da garantia estão em função do ambiente legal do país de domicílio e do setor ao qual a empresa pertence. Os resultados da pesquisa mostraram que as organizações não tomam por relevante se a prestadora de garantia é de natureza contábil, apontando o setor como o fator mais associado à decisão de as empresas assegurarem os $\mathrm{RS}$, com destaque para a indústria de mineração.

Gomes (2012), ao levantar o estado da arte dos RS das 117 maiores empresas portuguesas nos anos de 2008 a 2010, constatou o aumento das publicações dos relatórios de sustentabilidade nos últimos anos em Portugal, revelando que as diretrizes da GRI são as normas mais utilizadas pelas empresas para a elaboração dos RS. Com relação ao setor de 
atividade, os autores observaram que os setores que mais asseguram são "Serviços Públicos", seguidos das empresas de "Transporte e Logística".

Kolk e Perego (2010) avaliaram a influência dos fatores institucionais (ambiente jurídico, qualidade do ambiente jurídico e índice de responsabilidade corporativa) na adoção das declarações de garantia para os RS, com uma abordagem internacional das empresas do Fortune Global 250 nos anos de 1999, 2002 e 2005. Como variáveis de controle, foram atribuídas: tamanho da empresa, intensidade do uso dos ativos e setor. Os resultados evidenciaram que empresas que operam em países com sistema legal com base em code law, onde o desempenho empresarial atinge responsabilidades sociais que vão além da eficiência econômica, que possuem mecanismo de governança mais fracos e que sofrem uma maior pressão para sustentabilidade corporativa, estão mais propensas a adotarem os procedimentos de asseguração.

Ruhnke e Gabriel (2013), com base na Teoria da Agência, verificaram os fatores determinantes da procura pela garantia externa voluntária e empresas da Alemanha, Holanda e Grã-Bretanha. Os fatores investigados correspondem ao tamanho da empresa, dispersão de participação acionária, níveis de aplicação do GRI, departamento de sustentabilidade, experiência com emissão de relatórios de sustentabilidade, país, setor, ROA e alavancagem financeira. Os resultados demonstraram significância para os níveis de aplicação do GRI, departamento de sustentabilidade e tamanho da empresa, confirmando que os custos de agência desempenham um papel importante na decisão de procurar a verificação externa dos RS.

Zhou et al. (2013) examinaram o efeito das características do ambiente legal em nível de país sobre a decisão das empresas de assegurar as informações relativas a gases de efeito estufa (GEE) e da escolha do prestador de garantia, bem como se o efeito do ambiente legal dos países nessas decisões está condicionado às práticas de governança corporativa. Os autores observaram uma maior adesão pela asseguração em países mais orientados para os stakeholders, com sistemas de aplicação legal mais fracos e com estruturas de governança mais fortes. Quanto à escolha do provedor da garantia, constatou-se a preferência por provedores da profissão contábil para empresas de países mais orientados para os stakeholders; contudo, a força do sistema de aplicação legal não afetou significativamente essa preferência.

Cho et al. (2014) investigaram os fatores que levam as empresas dos EUA a assegurarem os RS e como essa prática é percebida pelos participantes do mercado. Os autores utilizaram um modelo de regressão logístico para empresas do Fortune Global 500 no ano de 2010. O estudo investigou a relação entre a garantia dos RS e o tamanho da empresa (receita total, ROA e alavancagem financeira); o setor ambientalmente sensível; o setor financeiro; a extensão dos relatórios; e o valor de mercado. No entanto, os resultados encontrados mostraram que somente a extensão dos relatórios e o setor ambientalmente sensível influenciam a asseguração dos RS. Os autores sugerem que as pesquisas futuras avaliem esses mesmos fatores em outros países com emprego de análises longitudinais. 
Castelo Branco et al. (2014) examinaram os fatores da asseguração dos RS em Portugal considerando um período de crise econômica após 2008 e 2011 . O estudo investigou se tamanho, setor de atuação, lucratividade, alavancagem financeira, tipo de propriedade e status de listagem influenciam a decisão pela garantia externa. Os resultados demonstraram que tamanho e rentabilidade se destacam mais em tempos de crise.

Zaro, Pastre, e Alberton (2016) preocuparam-se em identificar os critérios que norteiam os auditores na emissão dos relatórios de asseguração constantes nos relatórios de sustentabilidade das empresas da carteira ISE 2013. Os resultados indicam a prática de asseguração por $69 \%$ das empresas; em $71 \%$ delas a prática de asseguração foi realizada por empresas de auditoria independentes. Ainda, o estudo observou que $90 \%$ das empresas que asseguraram os seus relatórios de sustentabilidade pertencem aos diferentes segmentos da B3 (Nível 1, Nível 2 e Novo Mercado).

Silveira et al. (2017) descreveram o estado da arte da asseguração externa dos relatórios de sustentabilidade das empresas que compõem o ISE 2016. Os autores investigaram a associação entre as características analisadas como variáveis qualitativas correspondentes aos setores (regulado ou não) e ao nível de Governança Corporativa (Novo Mercado ou não). A análise descritiva mostrou que $61 \%$ das empresas da carteira ISE 2016 que aderem ao procedimento de verificação externa dos relatórios de sustentabilidade atuam em setores regulados. Essa evidência corrobora o que dizem Simnett et al. (2009), de que fatores externos, como ambiente de operação ou tipo de setor podem ser considerados fatores relevantes para a decisão por parte das empresas em assegurarem seus relatórios de sustentabilidade.

Quanto às práticas de Governança Corporativa, Silveira et al. (2017) observaram que $54,3 \%$ das empresas pertencem ao Novo Mercado, o qual mostrou ser o nível predominante na carteira ISE 2016. Porém, o Teste de Fisher não sustentou os resultados qualitativos podendo ressaltar restrições com relação ao tamanho da amostra. Dos trabalhos de asseguração, $82,1 \%$ são realizados por empresas de auditoria e $17,9 \%$ por prestadoras de garantia de consultoria e especialização em sustentabilidade, o que ressalta o know-how e a credibilidade adquirida pelas empresas de auditoria contábil nesse segmento.

Martínez-Ferrero e García-Sánchez (2017) investigaram o efeito dos mecanismos de Governança Corporativa na decisão das empresas em garantir seus RS e na escolha do provedor de garantia em países com maior orientação para os stakeholders. Os fatores investigados estão relacionados à força da função de monitoramento do conselho, determinada pelo tamanho, pela independência e pela atividade do comitê de sustentabilidade. Os resultados fornecem evidências de que a garantia dos RS e a escolha da profissão contábil como provedor da garantia se associam positivamente à independência do conselho e à atividade do comitê de sustentabilidade. 


\section{PROCEDIMENTOS METODOLÓGICOS}

Para a coleta de dados, a técnica empregada foi a documental, por meio da qual são coletados os dados secundários das empresas, disponíveis em formas de relatórios, e que ainda não passaram por nenhuma análise estatística (Gil, 2008). O banco de dados é composto por informações referentes ao período de 2011 a 2015, coletadas em janeiro de 2017 e que foram retiradas das Demonstrações Financeiras Padronizadas (DFPs), RS, Relatório

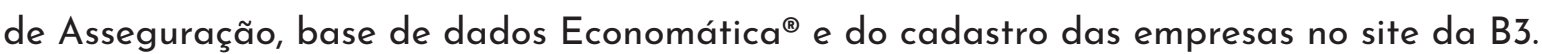

A população da pesquisa compreende as empresas listadas no índice $\mathrm{IBr} X-100$ pertencentes à carteira de janeiro a abril de 2017. As empresas listadas nesse índice refletem a carteira teórica composta por 100 ações selecionadas entre as mais negociadas na Brasil, Bolsa e Balcão (B3) em termos de liquidez, ponderadas na carteira pelo valor de mercado das ações disponíveis à negociação. A escolha dessa amostra justifica-se pela diversidade de setores de atuação das empresas; afinal, a premissa é de que essa amostra é representativa em relação ao mercado de ações brasileiro. Dessa população, foram excluídas as ações duplicadas (preferenciais e ordinárias) de cinco empresas (Bradesco, Petrobras, Vale, Eletrobras e Lojas Americanas). Ainda, 18 empresas-por não divulgarem RS ou por não apresentarem os dados selecionados para esta pesquisa- também foram eliminadas da amostra. Assim, a amostra final constitui-se em 77 empresas. A Tabela 1 apresenta a composição da amostra final da pesquisa:

Tabela 1

Composição da amostra final da pesquisa

\begin{tabular}{lrrrrr}
\hline \multicolumn{1}{c}{ Ano } & 2011 & 2012 & 2013 & 2014 & 2015 \\
\hline Amostra inicial (número de ações) & 100 & 100 & 100 & 100 & 100 \\
Empresas com duas ações no IBrX & $(5)$ & $(5)$ & $(5)$ & $(5)$ & $(5)$ \\
Não apresentaram RS em todos os anos & $(18)$ & $(18)$ & $(18)$ & $(18)$ & $(18)$ \\
Empresas com inconsistência & $(11)$ & $(9)$ & $(9)$ & $(7)$ & $(13)$ \\
Amostra final & 66 & 68 & 68 & 70 & 64 \\
\hline
\end{tabular}

Ressalta-se que, durante os cinco anos analisados (2011 a 2015), constam dados de 77 empresas. Contudo, anualmente o número de empresas pode variar, ou seja, algumas empresas não disponibilizaram dados para todos os anos desta pesquisa-por exemplo, a empresa Cielo S.A., que passou a emitir o RS a partir do ano de 2012. Portanto, a cada ano, partiu-se das 77 empresas e realizaram-se as análises somente com aquelas que apresentaram os dados anuais completos. Dessa forma, foram analisados 66 relatórios de sustentabilidade em 2011, 68 em 2012 e 2013, 70 em 2014 e 64 em 2015. 
As variáveis foram selecionadas conforme as evidências apontadas pelos estudos anteriores. Ainda, para operacionalizar esta pesquisa, os dados foram organizados em planilhas para a Análise de Correspondência (Anacor) e para Análise de Homogeneidade (HOMALS). Considerando que o foco dessas análises é o estudo da associação entre variáveis qualitativas, as variáveis Ativo, Receita Líquida, ROA, ROE e Endividamento foram divididas em quartis para categorizá-las em Alto $(X>Q 3)$, Médio $(Q 1<X \leq Q 3)$ e Baixo $(X \leq Q 1)$. A Tabela 2 demonstra a categorização e a definição atribuída para cada variável de interesse:

Tabela 2

Categorização e definição das variáveis

\begin{tabular}{lll}
\hline \multicolumn{1}{c}{ Variáveis } & Definição & $\begin{array}{c}\text { Nível de } \\
\text { associação }\end{array}$ \\
\hline Asseguração & Refere-se ao processo de verificação externa do RS. & Assegura \\
\cline { 2 - 3 } & $\begin{array}{l}\text { Representado pelo ramo de atividades que as empresas atuam no mercado } \\
\text { de ações brasileiro, as quais foram classificadas conforme a listagem da B3. }\end{array}$ & Pertence \\
\hline $\begin{array}{l}\text { Setor Regulado } \\
\text { (SETOR) }\end{array}$ & $\begin{array}{l}\text { Os setores foram diferenciados em regulados quando estes são regulados el } \\
\text { ou fiscalizados por uma agência reguladora de acordo com a Lei 8.987/95, } \\
\text { que define as agências reguladoras para diferentes setores de atuação. }\end{array}$ & Não pertence \\
\hline & Corresponde aos segmentos de listagem de Governanca Corporativa Dife- & Possui
\end{tabular}

Corresponde aos segmentos de listagem de Governança Corporativa Dife- Possui renciada da B3, e são diferenciados em Nível 1, Nível 2 e Novo Mercado.

Governança Cor- A diferenciação desses segmentos segue rígidas regras de $\mathrm{GC}$ que são porativa (CG) aderidas voluntariamente pelas empresas. As práticas de GC pressupõem confiabilidade e padronização das informações divulgadas (Gonçalves; \& Ott, 2002). Para a pesquisa, observou-se que a empresa está listada em algum dos níveis proposto pela B3.

Não possui

Representa a empresa ou o profissional independente que realizou o traba-

Prestadora da lho de asseguração dos relatórios de sustentabilidade. As empresas de conGarantia (AU. DIT) tabilidade que utilizaram procedimentos de auditoria foram classificadas como empresas de auditoria; já as empresas certificadoras e especialistas em sustentabilidade foram classificadas como empresas de não auditoria.

O GRI constitui-se em um conjunto de diretrizes para relatórios de sustentabilidade, de caráter não governamental, que abrange as dimensões econômica, social e ambiental (Castro et al., 2010). O GRI é considerado uma das ferramentas de comunicação mais completas e difundidas sobre as práticas socioambientais, visando ao desenvolvimento econômico sustentável (Gurvitsh \& Sidorova, 2012; Lozano \& Huisingh, 2011). Assim, Empresa de auditoria

Empresa de não auditoria Não se aplica Estrutura GRI verificou-se que o relatório de sustentabilidade emitido pelas empresas segue alguma das diretrizes propostas pelo GRI.

Índice de As empresas listadas na carteira ISE refletem o retorno das ações com Sustentabilidade os melhores desempenhos em aspectos de sustentabilidade empresarial Empresarial (ISE) (Brasil, Bolsa e Balcão, 2014). Identificou-se a participação das empresas no ISE para cada ano analisado.

Estrutura não GRI

Este classificou os setores em alto, médio e baixo de acordo com a Lei 10.165/00. Ressalta-se que para as empresas cujos setores não estão previstos na lei, como as empresas pertencentes ao setor de Financeiros e ao ISE

\begin{tabular}{l} 
Alto \\
\hline Médio \\
\hline
\end{tabular}

Impacto Outros, os setores foram classificados como baixos, pois os autores desta pesquisa entendem que toda a atividade exerce algum nível de impacto sobre o ambiente, ainda que de forma indireta ou de menor expressividade. Isso pode ser justificado pela própria iniciativa de estas empresas divulgarem e assegurarem as informações relativas à sustentabilidade. 


\begin{tabular}{|c|c|c|}
\hline Variáveis & Definição & $\begin{array}{l}\text { Nível de } \\
\text { associação }\end{array}$ \\
\hline \multirow{3}{*}{ Ativo Total } & \multirow{3}{*}{$\begin{array}{l}\text { Caracteriza o tamanho da empresa. As empresas maiores desenvolvem } \\
\text { atividades operacionais mais complexas, por isso, necessitam de maiores } \\
\text { informações sobre suas atividades (Wallace \& Naser, 1995). }\end{array}$} & Alto \\
\hline & & Médio \\
\hline & & Baixo \\
\hline \multirow{3}{*}{$\begin{array}{l}\text { Receita Opera- } \\
\text { cional Líquida }\end{array}$} & \multirow{3}{*}{$\begin{array}{l}\text { Configura-se como receita bruta menos as suas deduções. Esse indicador } \\
\text { fornece informações sobre o quanto um negócio pode ser rentável e com- } \\
\text { petitivo. }\end{array}$} & Alto \\
\hline & & Médio \\
\hline & & Baixo \\
\hline \multirow{3}{*}{ ROA } & \multirow{3}{*}{$\begin{array}{l}\text { Representa a "taxa de retorno gerada pelas aplicações realizadas por } \\
\text { uma empresa em seus ativos" - Lucro Líquido/Ativo (Assaf, 2007). }\end{array}$} & Alto \\
\hline & & Médio \\
\hline & & Baixo \\
\hline \multirow{3}{*}{ ROE } & \multirow{3}{*}{$\begin{array}{l}\text { Rentabilidade do patrimônio líquido (ROE): demonstra a rentabilidade } \\
\text { em resposta aos recursos dos acionistas em relação aos recursos totais da } \\
\text { empresa (Lucro Líquido/Patrimônio Líquido) (Zoboli Dalmacio, Rezende, } \\
\text { \& Slomski, 2009). }\end{array}$} & Alto \\
\hline & & Médio \\
\hline & & Baixo \\
\hline \multirow{3}{*}{$\begin{array}{l}\text { Endividamento } \\
\text { (ENDIV) }\end{array}$} & \multirow{3}{*}{$\begin{array}{l}\text { Esse índice revela o grau de endividamento da empresa, indicando a pro- } \\
\text { porção de ativos que estão comprometidos pelas obrigações das empresas } \\
\text { assumidas no período. Assim, divide-se a soma do Passivo Circulante e } \\
\text { Não Circulante pelo Ativo Total. }\end{array}$} & Alto \\
\hline & & Médio \\
\hline & & Baixo \\
\hline \multirow{2}{*}{$\begin{array}{l}\text { American Depo- } \\
\text { sitary Receipts } \\
(A D R)\end{array}$} & \multirow{2}{*}{$\begin{array}{l}\text { As } A D R s \text { são negociadas em Nível } 1,2 \text { e } 3 \text {, conforme as exigências } \\
\text { regulatórias e de disclosure diferenciadas para cada um dos níveis. Para } \\
\text { este trabalho, o comportamento de interesse é se a empresa emitiu ou não } \\
\text { ADR durante o período de análise. }\end{array}$} & Emite \\
\hline & & Não emite \\
\hline
\end{tabular}

\section{APRESENTAÇÃO DOS RESULTADOS}

O levantamento de dados contemplou o exame de 336 RS. As empresas que compõem a amostra pertencem a nove setores distintos, de acordo com a classificação pela B3. A Tabela 3 apresenta o número de relatórios assegurados e não assegurados durante os cincos anos de análise por setor de atuação das empresas:

Tabela 3

Asseguração por setores de atuação

\begin{tabular}{lccccc}
\hline \multirow{2}{*}{ Setor de atuação } & \multicolumn{2}{c}{ Assegura } & \multicolumn{2}{c}{ Não assegura } \\
\cline { 2 - 6 } & Quantidade & $\%$ & Quantidade & $\%$ & Total \\
\hline Bens Industriais & 11 & $28 \%$ & 28 & $72 \%$ & 39 \\
Consumo Cíclico & 5 & $11 \%$ & 42 & $89 \%$ & 47 \\
Consumo Não Cíclico & 19 & $40 \%$ & 28 & $60 \%$ & 47 \\
Financeiro e Outros & 35 & $61 \%$ & 22 & $39 \%$ & 57 \\
Materiais Básicos & 29 & $59 \%$ & 20 & $41 \%$ & 49 \\
Petróleo, Gás e Biocombustíveis & 7 & $50 \%$ & 7 & $50 \%$ & 14 \\
Saúde & 5 & $100 \%$ & 0 & $0 \%$ & 5 \\
Telecomunicações & 10 & $100 \%$ & 0 & $0 \%$ & 10 \\
Utilidade Pública & 44 & $65 \%$ & 24 & $35 \%$ & 68 \\
\hline Total & 165 & $49 \%$ & 171 & $51 \%$ & 336 \\
\hline
\end{tabular}


Dos 336 RS analisados no período, foi possível verificar que 165 (49\%) dos relatórios foram assegurados, enquanto 171 (51\%) não tiveram suas informações asseguradas.

Conforme demonstra a Tabela 3, o setor que apresentou maior índice de asseguração dos relatórios foram os setores de Telecomunicações e Saúde, ambos com 100\% de seus relatórios assegurados. Outros setores também se destacaram: Utilidade Pública com $65 \%$ dos RS assegurados, enquanto o setor Financeiro e Outros obteve 61\% dos relatórios assegurados. Por outro lado, as empresas que apresentaram menor índice de asseguração dos RS pertencem ao setor Consumo Cíclico, seguido pelas empresas do setor de Bens Industriais, corroborando Gomes (2012), que constatou que os setores que mais asseguram são Serviços Públicos e das empresas de Transporte e Logística.

A partir da Tabela 4, verificam-se as estatísticas descritivas das variáveis quantitativas, considerando o período de 2011 a 2015:

Tabela 4

Estatística descritiva

\begin{tabular}{lllll}
\hline \multicolumn{1}{c}{ Variáveis } & \multicolumn{1}{c}{ Média } & \multicolumn{1}{c}{ Desvio padrão } & \multicolumn{1}{c}{ Mínimo } & \multicolumn{1}{c}{ Máximo } \\
\hline Ativo & $92.855 .112,08^{*}$ & $248.962 .190,46^{*}$ & $286.912,00^{*}$ & $1.437 .485 .512,00^{*}$ \\
Receita Líquida & $25.133 .732,11^{*}$ & $51.085 .929,02^{*}$ & $183.517,00^{*}$ & $337.260 .000,00^{*}$ \\
ROA & 4,65 & 5,92 & $-16,76$ & 26,30 \\
ROE & 11,71 & 25,26 & $-206,44$ & 216,69 \\
Endividamento & 0,59 & 0,19 & 0,08 & 1,05 \\
\hline
\end{tabular}

Nota. ${ }^{*}$ Valores em reais.

A média do valor total do Ativo das empresas ficou em $\mathrm{R} \$ 92.855 .112,08$ e a Receita Líquida ficou em $\mathrm{R} \$ 25.133 .732,11$. Observa-se que, pelos valores de máximo e mínimo e também pelo desvio padrão, há dispersão das variáveis, o que indica a heterogeneidade da amostra. Embora sejam as 100 ações mais líquidas, as empresas pertencem a setores distintos e exercem atividades diferentes, o que acaba refletindo, assim, em seus números contábeis. A única variável que apresenta um comportamento mais homogêneo é a do Endividamento, indicando que, embora sejam diferentes, as empresas tendem a manter um nível de endividamento parecido.

A técnica de Anacor foi empregada para verificar a relação entre duas variáveis nominais em complemento ao Teste Qui-quadrado. O Teste Qui-quadrado identifica em cada ano as variáveis associadas à asseguração dos relatórios de sustentabilidade, conforme os resultados do teste na Tabela 5: 
Tabela 5

Teste Qui-quadrado

\begin{tabular}{clllllllllllr}
\hline Ano & Impacto & Ativo & Receita & ROA & ROE & Endiv. & ADR & Setor & ISE & GG & Audit. & GRI \\
\hline 2011 & 0,056 & 0,018 & 0,010 & 0,004 & 0,078 & 0,255 & 0,062 & 0,016 & 0,000 & 0,208 & 0,000 & 0,001 \\
2012 & 0,065 & 0,015 & 0,023 & 0,003 & 0,676 & 0,035 & 0,329 & 0,001 & 0,002 & 0,087 & 0,000 & 0,000 \\
2013 & 0,745 & 0,034 & 0,034 & 0,064 & 0,778 & 0,054 & 0,446 & 0,001 & 0,001 & 0,074 & 0,000 & 0,002 \\
2014 & 0,737 & 0,036 & 0,014 & 0,008 & 0,235 & 0,024 & 0,448 & 0,001 & 0,000 & 0,202 & 0,000 & 0,008 \\
2015 & 0,552 & 0,039 & 0,013 & 0,709 & 0,096 & 0,096 & 0,469 & 0,001 & 0,000 & 0,185 & 0,000 & 0,018 \\
\hline
\end{tabular}

Nesta pesquisa, adotou-se o nível de significância de 5\%; assim, com base no Teste Qui-quadrado, pode-se considerar que duas variáveis possuem associação quando sig. $\mathrm{X} 2=0,000<0,05$. De acordo com a Tabela 5, ao longo de todos os anos analisados, seis variáveis apresentaram sig. $\mathrm{X} 2<0,05$, indicando associações positivas para Ativo, Receita, Setor Regulado, ISE, Auditoria e GRI. E essas evidências corroboram os estudos de Simnett et al. (2009); Ruhnke e Gabriel (2013); Zhou et al. (2013); Castelo Branco et al. (2014); Silveira et al. (2017); e Martínez-Ferrero e García-Sánchez (2017).

Em seguida, apresenta-se a análise de homogeneidade, a qual mostra a associação entre mais de duas variáveis qualitativas por meio de mapas perceptuais. Os mapas perceptuais a seguir demonstram o grau de associação da asseguração dos RS com as variáveis que se mostraram significantes em todos os anos com base no Teste Qui-quadrado, conforme ilustra a Tabela 5. A Figura 1 apresenta o Mapa Perceptual de 2011:

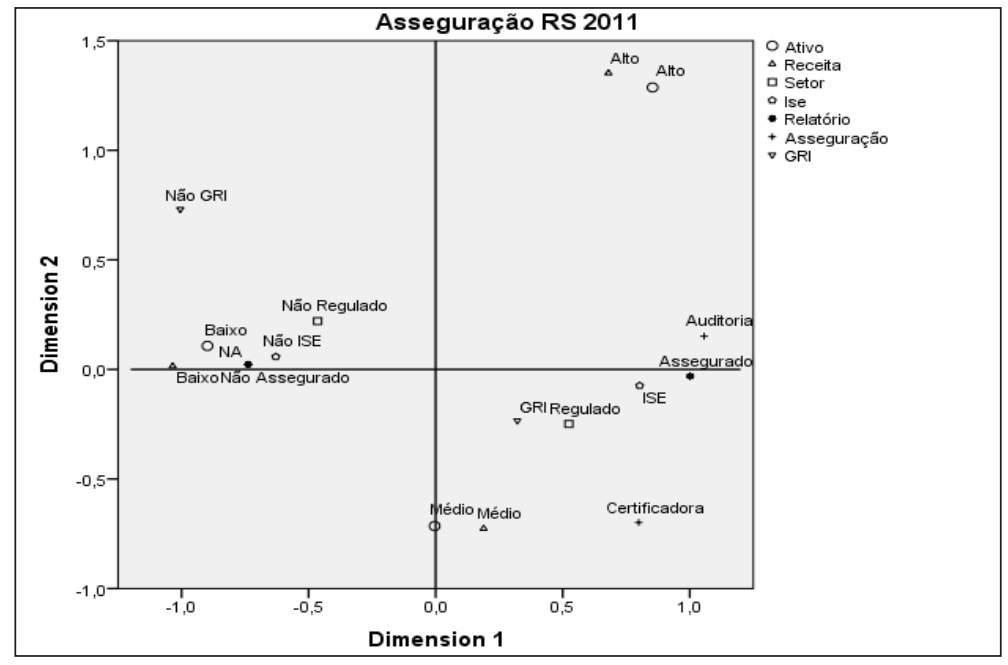

Figura 1. Mapa Perceptual 2011

Com base no Mapa Perceptual da Figura l, constata-se que no ano de 2011 a asseguração dos RS estava associada às variáveis Setor regulado, GRI, ISE e Auditoria. Isso demonstra que em 2011 as empresas que asseguraram seus RS pertenciam ao ISE (Setor Regulado); elaboraram seus relatórios com base no padrão GRI e estes foram assegurados por empresas de auditoria. Esse resultado corrobora os estudos de Gomes (2012); Zhou et al. 
(2013); Zaro et al. (2016); Silveira et al. (2017) e Martínez-Ferrero e García-Sánchez (2017), os quais constataram que as empresas de auditoria são responsáveis pela maioria dos trabalhos de asseguração dos RS; além disso, demonstra que esses relatórios seguem o padrão GRI (Ruhnke \& Gabriel, 2013). O Mapa também mostra que a não asseguração dos relatórios está associada às variáveis Setor Não Regulado, Não ISE, Ativo Baixo, e Receita Líquida Baixa.

A Figura 2 apresenta o Mapa Perceptual com associações encontradas para 2012:

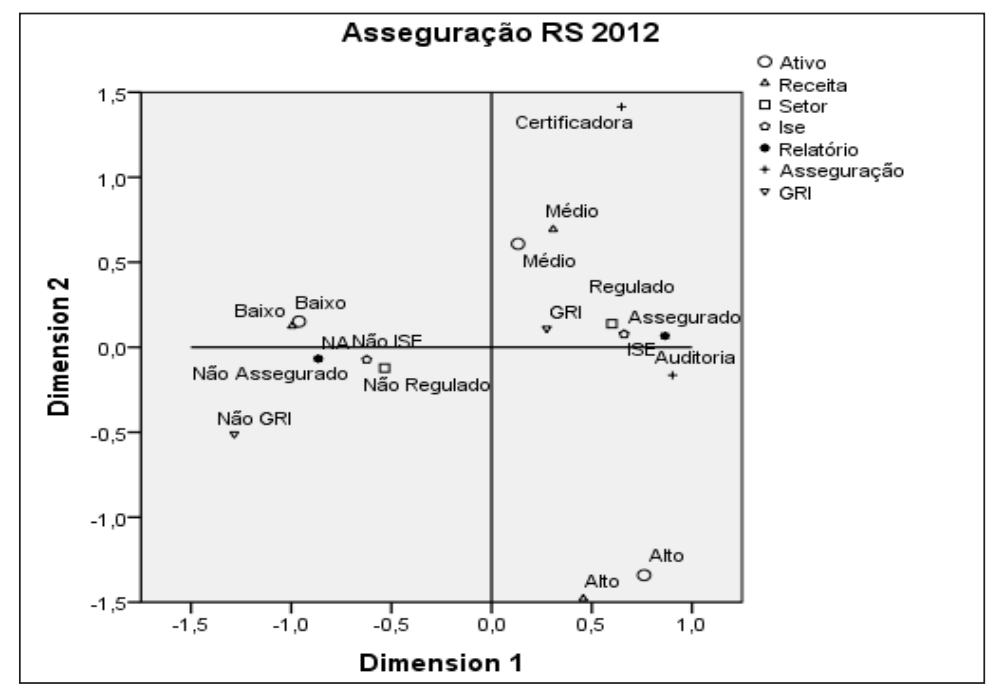

Figura 2. Mapa Perceptual 2012

Em 2012, a asseguração dos relatórios de sustentabilidade se mostrou mais associada às variáveis ISE, Auditoria, Setor Regulado, GRI e também agora às variáveis Ativo e Receita Líquida, ambas classificadas em médio. A não asseguração permaneceu associada às mesmas variáveis apresentadas no ano de 2011. A Figura 3 apresenta o Mapa Perceptual com associações encontradas para 2013:

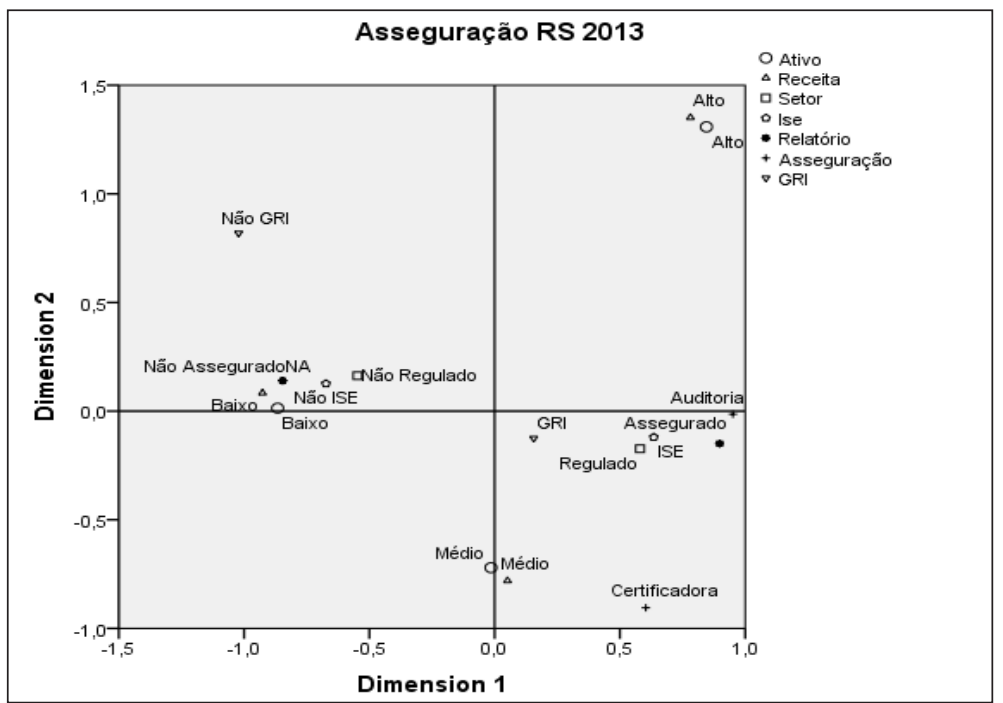

Figura 3. Mapa Perceptual 2013 
Em 2013, a asseguração dos relatórios permaneceu associada às mesmas variáveis que se mostraram associadas no ano de 2011: GRI, Setor Regulado, ISE e Auditoria. Em 2014, as variáveis que se mostraram mais associadas ao processo de asseguração dos RS também não sofreram alteração, permanecendo as mesmas, porém com uma aproximação da variável Certificadora, mostrando que o processo de asseguração foi realizado por empresas certificadoras e não somente por empresas de auditoria (Figura 4). A Figura 4 apresenta o Mapa Perceptual com associações encontradas para 2014:

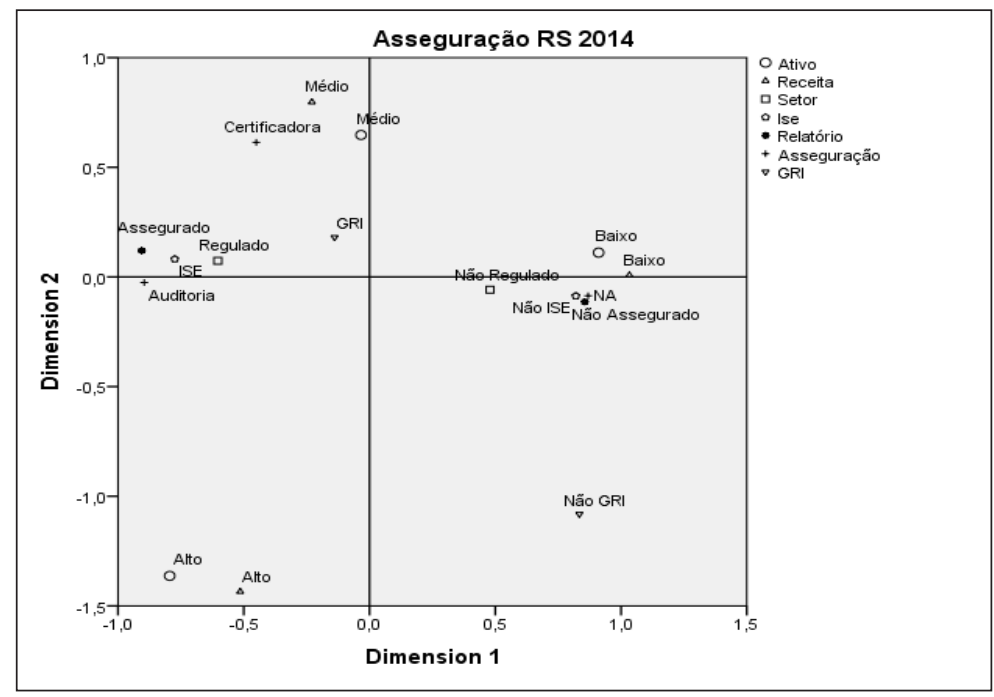

Figura 4. Mapa Perceptual 2014

No último ano analisado, como mostra a Figura 5, é possível verificar que as variáveis Auditoria, Setor Regulado, ISE e GRI permaneceram associadas à asseguração dos relatórios, embora um pouco mais distantes. Ainda, as variáveis Ativo Médio e Receita Líquida se mostraram associadas à prática de asseguração dos relatórios de sustentabilidade. A Figura 5 apresenta o Mapa Perceptual com associações encontradas para 2015:

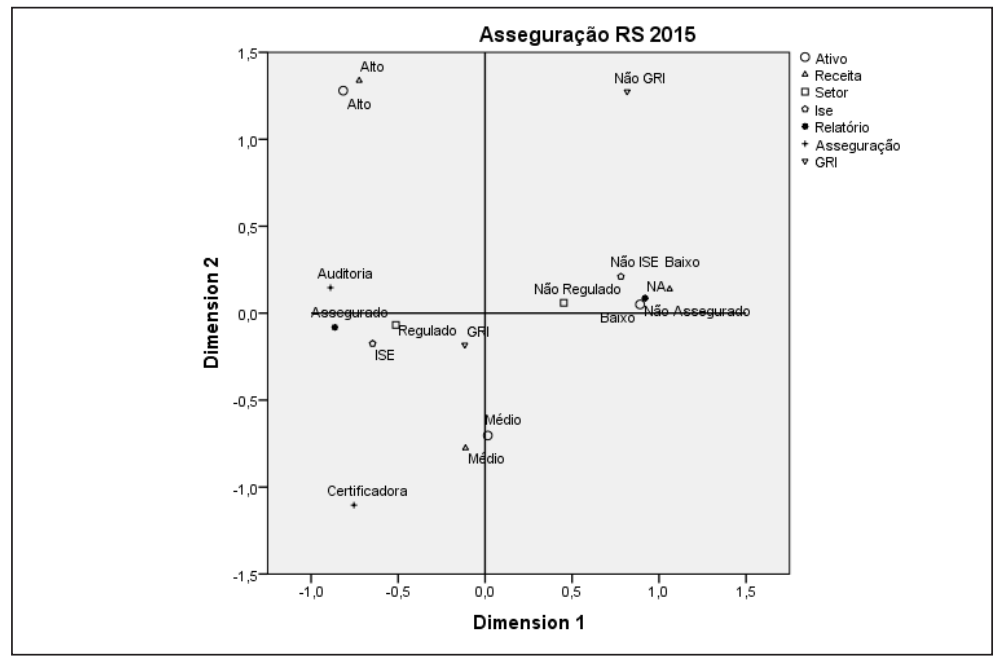

Figura 5. Mapa Perceptual 2015 
Já a não asseguração dos RS em 2015 se mostrou associada às variáveis Setor não Regulado, Não participar do ISE, Ativo e Receita Líquida, que foram classificadas como baixas. Isso indica que as empresas que não participaram do ISE 2015 não pertenciam a um setor regulado, e, quando comparadas com as demais empresas da amostra, as que possuíam um Ativo e uma Receita Líquida menor foram as que não submeteram seus relatórios à asseguração externa.

\section{DISCUSSÃO DOS RESULTADOS}

Quanto à quantidade de RS divulgados, este estudo observou que $49 \%$ destes foram assegurados. Assim, por mais que as empresas divulguem informações sobre sustentabilidade, a asseguração ainda é algo que não é praticado pela maioria das empresas analisadas neste estudo, já que o processo de asseguração é uma prática voluntária.

Nesse sentido, Silveira et al. (2017), ao analisarem a asseguração dos RS das empresas pertencentes ao ISE 2016, constataram que cerca de $80 \%$ das empresas submeteram seus relatórios à asseguração externa. Isso pode se justificar pelo fato de o ISE ser um indicador que tem como principal aspecto a sustentabilidade empresarial, fazendo com que as empresas que participam desse índice tenham uma maior responsabilidade socioambiental.

Com base no Teste Qui-quadrado, seis variáveis se mostraram significantes em todos os anos. Já pela análise dos Mapas Perceptuais, quatro variáveis se mostraram mais associadas à asseguração dos relatórios de sustentabilidade em todos os anos, sendo elas: Setor Regulado, ISE, GRI e Auditoria. Esse resultado vai ao encontro dos estudos de Gomes (2012); Zhou et al. (2013); Zaro, Pastre, e Alberton (2016); Silveira et al. (2017) e Martínez-Ferrero e GarcíaSánchez (2017), em que a asseguração dos RS é realizada em sua maioria por empresas de auditoria, e o padrão mais seguido pelos relatórios é o GRI; mas, opõe-se ao estudo de Simnett et al. (2009), por meio do qual se verificou que as empresas não consideram relevante a asseguração dos relatórios apenas por empresas de auditoria ou certificadora; mas, nesta pesquisa, a asseguração se mostrou mais associada à empresa de auditoria.

Porém, em relação à associação com o setor de atuação ser regulado, verifica-se que o resultado confirma o estudo de Simnett et al. (2009), pois esses autores mencionam que fatores externos-como o ambiente de operação ou o tipo de setor-podem ser considerados fatores relevantes para a decisão de as empresas submeterem os seus relatórios à verificação externa.

No cenário brasileiro, este estudo não pôde confirmar as evidências encontradas por Ruhnke e Gabriel (2013) e Martínez-Ferrero e García-Sánchez (2017) no que se refere à associação entre a asseguração e os níveis diferenciados de governança das empresas. Essa evidência também não foi confirmada estatisticamente por Silveira et al. (2017) para 
as empresas ISE 2016, visto que tais autores enfatizam a importância do tamanho e da diversificação da amostra.

Em relação à variável ISE estar associada à asseguração, como esse índice tem por objetivo refletir o retorno com base no desempenho sustentável empresarial, infere-se que as empresas participantes buscam uma maior credibilidade em suas ações socioambientais perante seus stakeholders por meio da prática de assegurar os seus relatórios.

Além disso, este estudo trouxe fatores que estão associados à não asseguração dos RS, por meio dos Mapas Perceptuais. Foi possível verificar que empresas com Ativo e Receita Líquida classificados como baixos não adotam os serviços de asseguração dos RS. Isso pode ser explicado pelo custo atribuído a esses serviços, uma vez que as empresas tomam por relevante tal prática, quando os benefícios derivados dela são percebidos e, dessa forma, compensam os custos associados (Simnett et al., 2009).

\section{CONCLUSÃO}

A divulgação de informações de caráter socioambiental, buscando uma maior transparência e evidenciação por parte das empresas, vai ao encontro dos diversos interesses dos diferentes stakeholders por informações. Nesse sentido, o presente estudo objetivou identificar os fatores que estão associados à asseguração dos RS. Durante o período da pesquisa (2011 a 2015) foram analisados 336 Relatórios de Sustentabilidade, dos quais 165 (49\%) foram assegurados e 171 (51\%) não foram assegurados.

Por meio das Análises de Correspondência (Anacor) e Homogeneidade (HOMALS), este estudo concluiu que as variáveis ISE, GRI, Setor Regulado e Auditoria estão associadas à asseguração dos RS em todos os anos analisados. Dessa maneira, as empresas atuantes em setores regulados e com maiores práticas de sustentabilidade estão mais associadas à asseguração dos RS. Além disso, a asseguração é realizada em sua maioria por empresas de auditoria, e o padrão mais seguido para a elaboração dos relatórios é o GRI.

Quanto a assegurar ou não assegurar, ou seja, com relação aos fatores que implicam a decisão das empresas, os resultados apontam que determinados setores asseguram mais que outros, como Telecomunicações, Saúde, Utilidade Pública, Financeiro e Outros. Isso pode estar relacionado ao grau de legitimidade que necessitam para se manter no mercado ou para se adequar ao comportamento tido como comum ou respeitado dentro de um determinado setor (Meyer \& Rowan, 1977).

Ressalta-se, ainda, o fato de que as empresas que mais asseguraram estão associadas àquelas que possuem visão sistêmica de longo prazo, por estarem incluídas no ISE e aderirem ao padrão GRI. As empresas maiores (nesta pesquisa analisadas pelo Ativo e pela Receita) 
possuem mais recursos e podem certificar-se além do que é obrigatório. Nesse sentido, cabe aqui uma reflexão: "Será que as empresas não asseguram seus relatórios apenas por não possuírem recursos ou não compreenderem os serviços de asseguração?" Tal compreensão abrange a percepção da relação custo-benefício, além da falta de padronização dos serviços de garantia.

Em suma, os resultados desta pesquisa contribuem para a discussão sobre a temática de asseguração dos RS, sobretudo em contexto brasileiro, abrangendo os fatores que levam as empresas a investirem em Responsabilidade Socioambiental e, assim, a assegurarem seus relatórios de forma voluntária, além de fornecerem evidências sobre a expertise e a confiabilidade transmitida pela atuação das empresas de auditoria nesse ramo.

Esta pesquisa de cunho empírico não objetivou levantar ou testar hipóteses com base em alguma teoria específica; por isso, teve como sua principal limitação a inferência sobre a relação direta entre a decisão das empresas em assegurarem seus RS e os demais fatores analisados neste estudo. Assim, como sugestão para futuras pesquisas, recomenda-se o emprego de diferentes técnicas estatísticas que possam explicar ou identificar as causas que favoreçam a ocorrência desse evento em painel brasileiro e internacional. Ademais, estudos futuros podem estabelecer essa relação com embasamento teórico fornecido pela Teoria da Legitimidade, uma das teorias que explicam a adoção de determinadas práticas voluntárias pelas organizações.

\section{REFERÊNCIAS}

Almeida, J. B. (2014). Asseguração de relatórios de sustentabilidade: O caso Petrobrás. Anais do Congresso USP de Controladoria e Contabilidade, São Paulo, 14.

Assaf, A., Neto. (2007). Estrutura e análise de balanços: Um enfoque econômico-financeiro. São Paulo: Atlas.

Brasil, Bolsa e Balcão. Securities, Commodities and Futures Exchange. (2014). Recuperado de http://www.bmfbovespa.com.br

Castelo Branco, M., Delgado, C., Ferreira Gomes, S., \& Cristina Pereira Eugénio, T. (2014). Factors influencing the assurance of sustainability reports in the context of the economic crisis in Portugal. Managerial Auditing Journal, 29(3), 237-252. Recuperado de https:// www.emeraldinsight.com/doi/abs/10.1108/MAJ-07-2013-0905

Castro, F. A. R., Siqueira, J. R. M. de, \& da Silva Macedo, M. Á. (2010). Indicadores ambientais essenciais: Uma análise da sua utilização nos relatórios de sustentabilidade das empresas do setor de energia elétrica sul americano, elaborados pela versão "G3" da Global Reporting Initiative. Revista de Informação Contábil, 4(4), 83-102. 
Cho, C. H, Michelon, G., Patten, D. M., \& W. Roberts, R. (2014). CSR report assurance in the USA: An empirical investigation of determinants and effects. Sustainability Accounting, Management and Policy Journal, 5(2), 130-148. Retrieved from https://www.emeraldinsight.com/doi/abs/10.1108/SAMPJ-01-2014-0003

Conselho Federal de Contabilidade. (2015a). Comunicado Técnico CTO Ol-Emissão de Relatório de Asseguração Relacionado com Sustentabilidade e Responsabilidade Social.

Conselho Federal de Contabilidade. (2015b). NBC TA-Estrutura Conceitual.

Conselho Federal de Contabilidade. (2009). NBC TO 3000-Trabalho de Asseguração Diferente de Auditoria e Revisão.

Deegan, C., Cooper, B. J., \& Shelly, M. (2006). An investigation of TBL report assurance statements: UK and European evidence. Managerial Auditing Journal, 21(4), 329-371.

Retrieved from https://www.emeraldinsight.com/doi/abs/10.1108/02686900610661388

Gil, A. C. (2008). Métodos e técnicas de pesquisa social. (6ª ed.). São Paulo: Atlas.

Global Reporting Initiative. (2013). The external assurance of sustainability reporting. Research and Development Series.

Gomes, S. F. (2012). Auditoria aos relatórios de sustentabilidade das empresas portuguesas: Uma visão sobre o estado da arte e a percepção dos Revisores Oficiais de Contas (Dissertação de mestrado). Escola Superior de Tecnologia e Gestão, Leiria, Portugal.

Gonçalves, O., \& Ott, E. (2002). A evidenciação nas companhias brasileiras de capital aberto. Anais do Encontro Nacional da Anpad (Enanpad), São Paulo, 26.

Gurvitsh, N., \& Sidorova, I. (2012). Survey of sustainability reporting integrated into annual reports of Estonian companies for the years 2007-2010: Based on companies listed on Tallinn Stock Exchange as of October 2011. Procedia Economics and Finance, 2, 26-34. Retrieved from https://www.sciencedirect.com/science/article/pii/S2212567112000615

Hasan, M., Roebuck, P. J., \& Simnett, R. (2003). An investigation of alternative report formats for communicating moderate levels of assurance. Auditing: A Journal of Practice \& Theory, 22(2), 171-187. Retrieved from https://www.aaajournals.org/doi/abs/10.2308/ aud.2003.22.2.171 
Hodge, K., Subramaniam, N., \& Stewart, J. (2009). Assurance of sustainability reports: Impact on report user's confidence and perceptions of information credibility. Australian Accounting Review, 19(3), 178-194. Retrieved from https://onlinelibrary.wiley.com/doi/ abs/10.1111/j.1835-2561.2009.00056.x

Kolk, A., \& Perego, P. (2010). Determinants of the adoption of sustainability assurance statements: An international investigation. Business Strategy and the Environment, 19(3), 182-198. Retrieved from https://onlinelibrary.wiley.com/doi/abs/10.1002/bse.643

KPMG International survey of corporate responsibility reporting 2011. (2011). Amsterdam, The Netherlands: KPMG.

KPMG International survey of corporate responsibility reporting 2015. (2015). Amsterdam, The Netherlands: KPMG.

Lozano, R., \& Huisingh, D. (2011). Inter-linking issues and dimensions in sustainability reporting. Journal of Cleaner Production, 19(2), 99-107. Retrieved from https://www.sciencedirect.com/science/article/pii/S0959652610000156

Martínez-Ferrero, J., \& García-Sánchez, I. M. (2017). Sustainability assurance and assurance providers: Corporate governance determinants in stakeholder-oriented countries. Journal of Management \& Organization, 23(5), 647-670. Retrieved from https://www.cambridge. org/core/journals/journal-of-management-and-organization/article/sustainability-assurance-and-assurance-providers-corporate-governance-determinants-in-stakeholderoriented-countries/DF2E37ADD8C142422BAC1A1A7B638B7E

Meyer, J. W., \& Rowan, B. (1977). Institutionalized organizations: Formal structure as myth and ceremony. American Journal of Sociology, 83(2), 340-363.

Mori, R., Jr., Best, P. J., \& Cotter, J. (2014). Sustainability reporting and assurance: A historical analysis on a world-wide phenomenon. Journal of Business Ethics, 120(1), 1-11. Retrieved from https://link.springer.com/article/10.1007/s10551-013-1637-y

Patten, D. M. (1992). Intra-industry environmental disclosures in response to the Alaskan oil spill: A note on legitimacy theory. Accounting, Organizations and Society, 17(5), 471-475. Retrieved from https://www.sciencedirect.com/science/article/pii/036136829290042Q

Perego, P., \& Kolk, A. (2012). Multinationals' accountability on sustainability: The evolution of third-party assurance of sustainability reports. Journal of Business Ethics, 110(2), 173 190. Retrieved from https://link.springer.com/article/10.1007/s10551-012-1420-5 
Rover, S., Borba, J., Dal-Ri Murcia, F., \& Vicente, E. (2008). Divulgação de informações ambientais nas demonstrações contábeis: Um estudo exploratório sobre o disclosure das empresas brasileiras pertencentes a setores de alto impacto ambiental. Revista de Contabilidade e Organizações, 2(3), 53-72. Retrieved from https://www.revistas.usp.br/rco/ article/view/34713

Ruhnke, K., \& Gabriel, A. (2013). Determinants of voluntary assurance on sustainability reports: an empirical analysis. Journal of Business Economics, 83(9), 1063-1091. Retrieved from https://link.springer.com/article/10.1007/s11573-013-0686-0

Silveira, G. B., Alberton, L., \& Vicente, E. F. R. (2017). O Estado da Arte da Asseguração dos Relatórios de Sustentabilidade: Um Estudo das Empresas do Índice de Sustentabilidade Empresarial (ISE) 2016. Revista de Gestão Social e Ambiental, 11(2). Recuperado de https://rgsa.emnuvens.com.br/rgsa/article/view/1260

Simnett, R., Vanstraelen, A., \& Chua, W. F. (2009). Assurance on sustainability reports: An international comparison. The Accounting Review, 84(3), 937-967. Retrieved from https:// www.aaajournals.org/doi/abs/10.2308/accr.2009.84.3.937

Wallage, P. (2000). Assurance on sustainability reporting: An auditor's view. Auditing: A Journal of Practice \& Theory, 19(s-1), 53-65. Retrieved from https://www.aaajournals.org/ doi/abs/10.2308/aud.2000.19.s-1.53

Wallace, R. O., \& Naser, K. (1995). Firm-specific determinants of the comprehensiveness of mandatory disclosure in the corporate annual reports of firms listed on the stock exchange of Hong Kong. Journal of Accounting and Public policy, 14(4), 311-368. Retrieved from https://www.sciencedirect.com/science/article/pii/0278425495000429

Zaro, E., Pastre, F., S., \& Alberton, L. (2016). Asseguração dos relatórios de sustentabilidade das empresas que compõem a carteira do índice de sustentabilidade empresarial 2013. Revista de Contabilidade do Mestrado em Ciências Contábeis da UERJ, 20(1). Recuperado de http://www.atena.org.br/revista/ojs-2.2.3-06/index.php/UERJ/article/viewArticle/2865

Zhou, S., Simnett, R., \& Green, W. (2013). The effect of legal environment and corporate governance on the decision to assure and assurance provider choice: Evidence from the GHG assurance market. UNSW Australian School of Business Research Paper. A, 5.

Zoboli Dalmacio, F., Rezende, A. J., \& Slomski, V. (2009). Análise setorial das medidas de performance utilizadas nos contratos de remuneração dos gestores. Revista Universo Contábil, 5(3). Recuperado de http://gorila.furb.br/ojs/index.php/universocontabil/article/view/1524 


\section{Como citar este artigo:}

\section{ABNT}

SILVEIRA, Gabriela Borges et al. Assegurar ou não assegurar? Eis a questão: uma análise dos fatores associados à asseguração dos relatórios de sustentabilidade. RACE, Revista de Administração, Contabilidade e Economia, Joaçaba: Editora Unoesc, v. 18, n. 2, p. 259 280 maio/ago. 2019. Disponível em: http://editora.unoesc.edu.br/index.php/race. Acesso em: dia/mês/ano.

\section{APA}

Silveira, G. B., Ferreira, J. da S., Farias, R. B., Van Bellen, H. M., \& Rover, S. (2019). Assegurar ou não assegurar? Eis a questão: Uma análise dos fatores associados à asseguração dos relatórios de sustentabilidade. RACE, Revista de Administração, Contabilidade e Economia, 18(2), 259-280. Recuperado de http://editora.unoesc.edu.br/index.php/race 